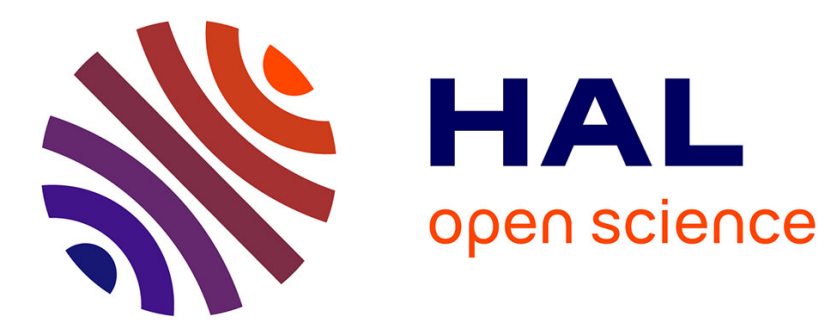

\title{
Photopyroelectric detection of organic vapors
}

\author{
W. Rumpler, H.-D. Liess
}

\section{To cite this version:}

W. Rumpler, H.-D. Liess. Photopyroelectric detection of organic vapors. Journal de Physique IV Proceedings, 1994, 04 (C7), pp.C7-507-C7-510. 10.1051/jp4:19947119 . jpa-00253172

\section{HAL Id: jpa-00253172 https://hal.science/jpa-00253172}

Submitted on 1 Jan 1994

HAL is a multi-disciplinary open access archive for the deposit and dissemination of scientific research documents, whether they are published or not. The documents may come from teaching and research institutions in France or abroad, or from public or private research centers.
L'archive ouverte pluridisciplinaire HAL, est destinée au dépôt et à la diffusion de documents scientifiques de niveau recherche, publiés ou non, émanant des établissements d'enseignement et de recherche français ou étrangers, des laboratoires publics ou privés. 
JOURNAL DE PHYSIQUE IV

Colloque C7, supplément au Journal de Physique III, Volume 4, juillet 1994

\title{
Photopyroelectric detection of organic vapors
}

\author{
W. Rumpler and H.-D. Liess \\ Institut für Physik, Fakultät für Elektrotechnik, Universität der Bundeswehr München, \\ Werner-Heisenberg-Weg 39, 85577 Neubiberg, Germany
}

\begin{abstract}
The photopyroelectric (PPE) detection of vapors under ambient conditions is demonstrated. A polymer film coated on the transducer is used as sensitive layer. Sorption within this layer binds and concentrates the vapor molecules at the detector surface. Monochromatic IR-radiation selectively excites the sorbed molecules and, therefore, the detected heat is a function of vapor concentration. Preliminary experiments yield a detection limit of $30 \mathrm{ppm}$ methanol vapor.
\end{abstract}

\section{Introduction}

The photo-thermal detection of gases or vapors by solid state detectors generally encounters problems associated with the large thermal mismatch between gases and the solid state. Binding the molecules of a gas directly to a surface of a pyroelectric element by physical adsorption $[1,2]$ is a first step toward solving this problem. However, due to limited number of sorption sites available on the surface, the total amount of heat, generated by optical excitation of the sorbed vapor molecules, is very low. In this work sorption enhancement achieved by depositing polymer layers on the detector surface and a final development of a photopyroelectric (PPE) system for detection of vapors are demonstrated.

The operational principle of the PPE-vapor-sensor is based on the interaction between the vapor and a sensitive polymer layer. Molecules of the gas or vapor enter the polymer by diffusion. Within the bulk of the polymer they are reversibly bounded and concentrated to a large extent in comparison to the gas phase. The partition coefficient expresses the ratio of the concentration of the gas molecules in the polymer and in the gas phase. A typical value of the partition coefficient in this work is 3.000 , indicating much higher concentration of gas molecules in the polymer. Consequently, the polymer has two functions: it does not only concentrate gas molecules very effectively, but also enables an efficient heat transfer from gas molecules to a solid state detector.

The polymer covered sensor is illuminated by intensity $\left(\mathrm{I}_{0}\right)$ modulated IR-radiation, as shown in Fig. 1. The beam initially traverses the gas in front of the detector losing some of its original intensity. 
Most of the intensity $(\Delta \mathrm{I})$ however is lost in the polymer by absorption and uncompleted reflection at the electrode. The main objective is, to use high reflective electrodes and polymers having very low self absorption. In this case only the sorbed gas molecules will absorb the light and generate the heat which is transported to the pyroelectric detector by a thermal wave. That is to say, that the amount of gas in the polymer governs the amplitude of the thermal wave detected by a pyroelectric element.

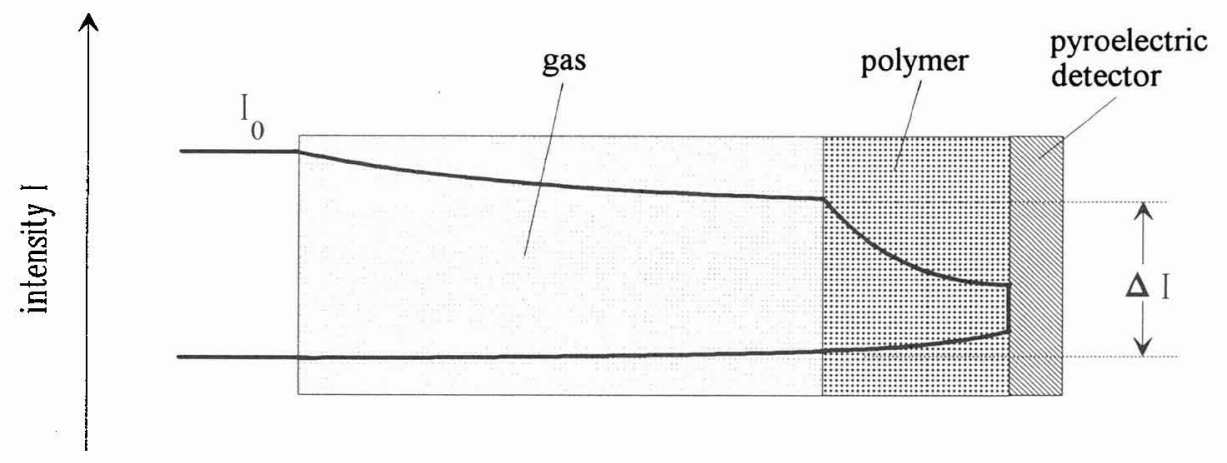

Figure 1: Absorption of IR-radiation in the gas phase in front of the sensor and within the polymer layer (extremely enlarged). The uncompleted reflection of light at the electrode of the pyroelectric detector is indicated by a step of intensity ( $\Delta I$ : loss of intensity, used for detection).

\section{Experimental}

The PPE-vapor-sensor consists of a pyroelectric transducer disc made of a polycrystalline PZTceramic (PXE5, Philips GmbH). Its diameter and thickness is $16 \mathrm{~mm}$ and $0.5 \mathrm{~mm}$, respectively. The disc is polarized parallel to its axes; the pyroelectric coefficient is about $420 \mu \mathrm{Cm}^{-2} \mathrm{~K}^{-1}$. The electrodes of the PZT-transducer are made of nickel. In order to increase the reflection of the sampling IR-beam, the active electrode is additionally sputtered with gold, that also prevents irreversible oxidation of the electrode. This might happen while sensing gases or vapors. The gold sputtered electrode is covered with a thin polymer film. For all experiments discussed here, the polymer polyvinylpyrrolidone (PVP) used by Grate et al. [3] was selected. The powder of PVP was dissolved in methanol $(99.9 \%)$; both products are from Merck. A solution of $0.7 \mathrm{~g}$ PVP in $20 \mathrm{ml}$ methanol was used in a home-made air brushing system to cover the gold electrode of the pyroelectric detector. After vacuum heating at $70^{\circ} \mathrm{C}$ for twelve hours the solvent has fully evaporated and a smooth thin (about $1 \mu \mathrm{m}$ ) PVP-film remained as sensitive layer on top of the detector.

The PZT-disc was mounted in a gas cell and connected directly to a current preamplifier (Ithaco Model 564). The output of the preamplifier was processed by Ithaco Model 3961B lock-in-amplifier and resulting data were collected in a standard PC via an IEEE-interface. Simultaneously, the amplitude of the thermal wave was monitored on a 1-channel-plotter.

All measurements were performed with Oriel 6575 IR-emitter, a ceramic element, similar to a Nernst. glower. The beam is focused by an elliptical $\mathrm{AlMgF}_{2}$-reflector (Oriel) and chopped mechanically at 
$30 \mathrm{~Hz}$ (Princeton Applied Research Model 192). A diffraction grating monochromator (Jobin-Yvon M25) was used to obtain monochromatic light especially in the finger-print region of the IR-spectrum.

The PPE-vapor-sensor operates with monochromatic light, that guarantees high selectivity when used in vapor mixtures. The experimental set-up, described above, enables performance of PPEspectroscopical study. Spectroscopic measurements are necessary due to a shift and/or broadening of absorption bands for a given molecule, when undergoing changes from gas to sorbed phase [4]. For a final version of vapor sensor, operating with monochromatic light, it is very important to find a wavelength, that is absorbed only by sorbed molecules and not by molecules in the gas phase. Fig. 1 indicates the reason why: any radiation, absorbed in the gas phase, would reduce the intensity of light reaching the detector and consequently also lower the signal. However, radiation emitted at wavelengths absorbed only by sorbed molecules prevents this. Therefore, PPE-spectra have to be obtained to find out proper wavelengths (here demonstrated for PVP/methanol system). After selecting a suitable wavelength, the monochromator can be replaced by an interference filter with a small bandwidth in order to enhance the throughput.

\section{Results and Discussion}

\subsection{PPE Spectra}

Methanol vapor exhibits a strong absorption band near $1020 \mathrm{~cm}^{-1}$ due to C-O-stretching vibrations. The PPE-spectroscopic examination of methanol with a PVP covered pyroelectric detector yields spectra in the region of $930-1090 \mathrm{~cm}^{-1}$ such as these in Fig. 2a and $2 \mathrm{~b}$. Dashed lines are obtained with a pure PVP, whereas solid lines represent data, when highly concentrated methanol vapor (15 $\%)$ is admitted to the gas cell.
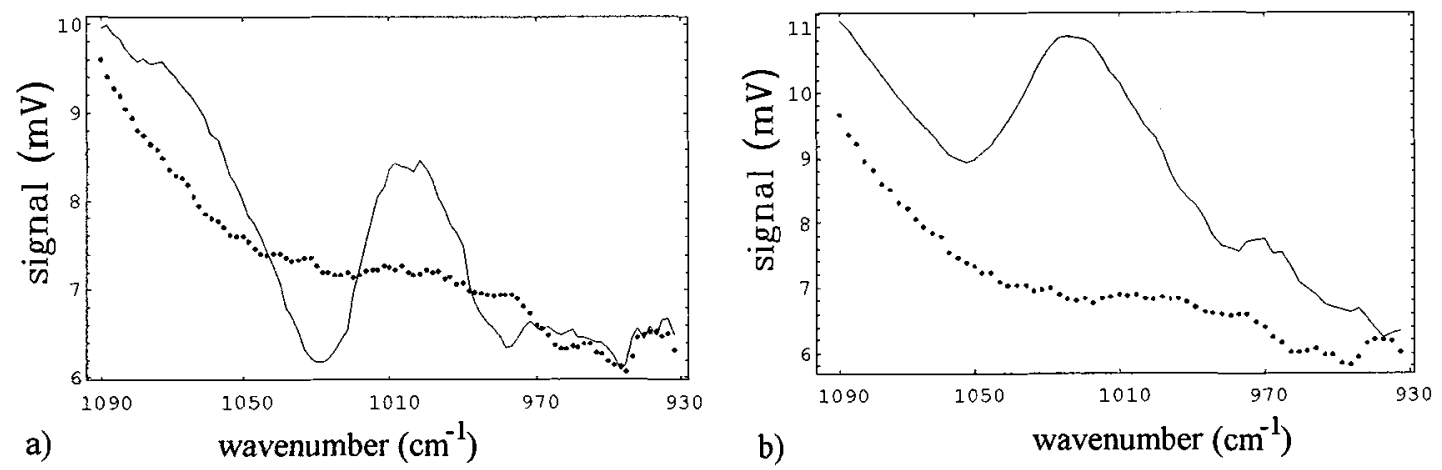

Figure 2: The PPE-spectrum of PVP recorded with (-) and without $(\cdots \cdots)$ methanol vapor (15 $\%$ ), when distance between window of the gas cell and detector was $10 \mathrm{~mm}$ (a) and $2 \mathrm{~mm}(\mathrm{~b})$.

Inspecting plots in Fig. 2a, one observes somewhat antagonistic addition of two different absorption bands. The explanation for this is: absorption in a gas phase reduces the signal $\left(1010-1060 \mathrm{~cm}^{-1}\right)$, while absorption by a sorbed phase enhances the signal $\left(1000-1080 \mathrm{~cm}^{-1}\right)$. If the distance between the cell window and the detector is reduced (from $10 \mathrm{~mm}$ to $2 \mathrm{~mm}$ ), the influence of the gas phase becomes negligible. This effect is shown in Fig. $2 \mathrm{~b}$, where no significant loss of signal is observed. 


\subsection{PPE-Vapor-Sensor for Methanol}

According to data from Fig. $2 b$ the monochromator should be replaced by an interference filter centred at $1020 \mathrm{~cm}^{-1}$, in order to get a selective sensor for methanol vapor. The response of the PPE-sensor to different concentrations of methanol vapor is shown in Fig. 3.

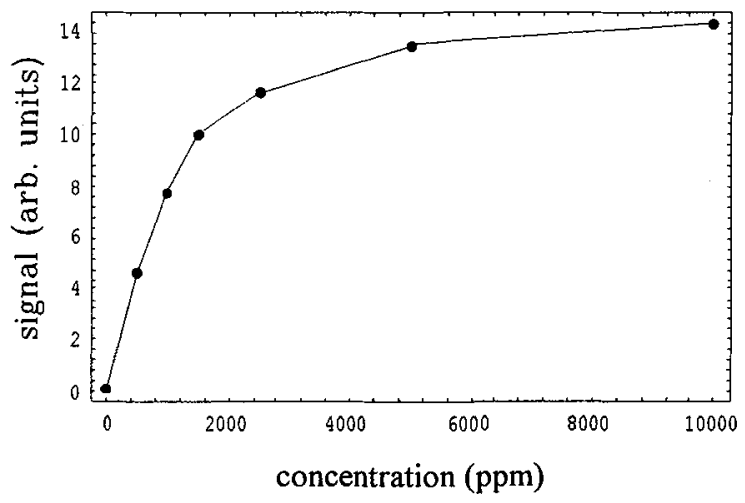

Figure 3: The response of PPE-sensor plotted versus varying concentration of methanol vapor at $\tilde{\nu}$ $=1020 \mathrm{~cm}^{-1}$.

The shape of sensor's response is typical for devices using polymer films for vapor detection [5]. The reduction of sensitivity at high concentration levels is due to a saturation of the polymer film by methanol vapor. Thus the PPE-vapor-sensor is most sensitive at lower concentration levels. Preliminary experiments with a PVP-coated sensor yield a detection limit of $30 \mathrm{ppm}$ methanol vapor in air.

High optical selectivity of the PPE-system is the major advantage of this device above other systems $[3,6]$ using sorption in polymers for sensing vapors and gases under ambient conditions.

\section{References}

[1] Träger F., Coufal H. and Chuang T.J., Phys. Rev. Lett. 49/23 (1982) 1720-1723.

[2] Zharov V.P. and Letokhov V.S., Laser Optoacoustic Spectroscopy (Springer Verlag, Berlin 1986) pp. 1-15.

[3] Grate J.W. and Abraham M.H., Sensors and Actuators B (1991) 1-27.

[4] Bradshaw A.M. and Schweizer E., Spectroscopy of Surfaces (John Wiley \& Sons, Chichester 1988) 413-483.

[5] Topart P. and Josowicz M., J. Phy. Chem. 96 (1992) 8662-8666.

[6] Ballantine D.S., Rose S.L., Grate J.W. and Wohltjen H., Anal. Chem. 58 (1986) 3058-3066. 